\title{
Perceived Organizational Support Associated with Depressive Symptoms Among Petroleum Workers in China: A Cross-Sectional Study
}

This article was published in the following Dove Press journal: Psychology Research and Behavior Management

\author{
Zhi-Hui Gu \\ Tian Qiu \\ Fang-Qiong Tian \\ Shi-Han Yang (D) \\ Hui Wu
}

Department of Social Medicine, School of Public Health, China Medical University, Shenyang I I0000, People's Republic of China
Correspondence: Hui Wu Email hwu@cmu.edu.cn
Objective: The objective of this study was to explore the association between perceived organizational support (POS) and depressive symptoms, and to further explore whether selfefficacy can act as a moderator between POS and depressive symptoms among Chinese petroleum workers.

Methods: There was a cross-sectional study conducted at a petrochemical enterprise in Liaoning Province, China, from July to August 2018. A series of questionnaires were accomplished by 1836 petroleum workers, including the Center for Epidemiologic Studies Depression Scale (CES-D), the Survey of Perceived Organizational Support (SPOS), and the General Self-Efficacy Scale (GSES). Hierarchical regression analysis was used to examine the relationship of SPOS score, GSES score, and SPOS score $\times$ GSES score interaction with CES-D score. A simple slope analysis will be carried out if the interaction has statistical significance.

Results: Hierarchical regression analysis showed that SPOS score $(\beta=-0.538, P<0.01)$ and GSES score $(\beta=-0.313, P<0.01)$ played a main influence on CES-D score. The SPOS score $\times$ GSES score interaction term significantly explained an extra $9.7 \%$ of the variance ( $F=253.932$, adjusted $R^{2}=0.582, \Delta R^{2}=0.097, P<0.01$ ). The interaction term was positively correlated with CES-D score $(\beta=0.334, P<0.01)$. The relationship between SPOS score and CES-D score gradually decreased in the low ( 1 SD below the mean, $\beta=-0.589, P<0.01$ ), mean $(\beta=-0.338, P<0.01)$, and high ( $1 \mathrm{SD}$ above the mean, $\beta=-0.087, P<0.01)$ groups of GSES score.

Conclusion: This study showed that POS and self-efficacy played a main influence on depressive symptoms, and the interaction term was positively correlated with depressive symptoms. Self-efficacy could attenuate the association between POS and depressive symptoms. It suggests that appropriate POS and self-efficacy enhancement measures ought to be supplied to relieve depressive symptoms.

Keywords: moderating role, depressive symptoms, perceived organizational support, selfefficacy, petroleum workers

\section{Introduction}

Depression is one of the main mental diseases affecting human health. ${ }^{1}$ The World Health Organization reported an annual prevalence of depression of $9.5 \%$ in women and $5.8 \%$ in men. ${ }^{2}$ Depression is also prevalent in the labor force, and the research reports from different countries show that depressive symptoms are common in the workplace. $^{3-5}$ In recent years, the investigation found that almost half of the occupational groups have depressive symptoms in China, ${ }^{6}$ including teachers, 
traffic police, administrators, community health workers, employees of foreign enterprises, and researchers. ${ }^{7}$ In addition to the high prevalence of depression, it also influences the productivity and overall job performance of workers in the workplace. ${ }^{8}$ Workers with depression may have higher rates of absenteeism, turnover willingness, and even stoppage. ${ }^{9,10}$

At present, there are many investigations on depressive symptoms and their psychological factors in different groups in China. ${ }^{11,12}$ However, few studies have reported the prevalence of depressive symptoms among petroleum workers in China, especially the relationship between coping resources and depressive symptoms. The petrochemical industry has been a high-risk industry, which involves exploration, oil recovery, transportation, processing, deep processing, and other links. Petroleum workers have been exposed to special working conditions for a long time, including kinds of physical stressors, such as bad weather conditions, shifts, night shifts, long working hours, noise, vibration, and poor ventilation. ${ }^{13}$ These conditions are considered to present a significant effect on physical and mental health. ${ }^{14}$ Work conditions, including occupational category, shift work, night duty, long working hours, and occupational mental factors, including working pressure, self-efficacy, and perceived social support, have been identified as predictors of depression. ${ }^{15}$ Therefore, the study of depressive symptoms and related factors in petroleum workers will help to formulate effective intervention measures for the population.

Perceived organizational support (POS) means that employees form a generalized perception concerning the extent to which the organization values their contributions and cares about their well-being. ${ }^{16}$ POS also fulfills socioemotional needs, resulting in greater identification and commitment to the organization, greater psychological well-being, and workers may be happier in their jobs when they see the organization as dispositionally supportive. ${ }^{17}$ POS is considered an efficient organizational resource that can produce positive work attitudes and results, and also has a positive impact on people's mental health. ${ }^{18,19}$ It has been identified as a positive resource for alleviating depressive symptoms. ${ }^{20,21}$ It can be concluded that when employees feel high organizational support, they will be more enthusiastic and happy, and the probability of depression will be reduced. At the same time, self-efficacy also has this function. Self-efficacy refers to the belief in one's competence to cope with a broad range of stressful or challenging demands. $^{22}$ Self-efficacy can affect a person's behavior choice and determines the extent and duration of their efforts when a person has to face obstacles or suffering, and selfefficacy also can affect people's thinking and emotional response patterns. ${ }^{23}$ Many research studies have shown that self-efficacy has a direct positive impact on depression. ${ }^{24,25}$ With higher self-efficacy, depressive symptoms became lighter. Also, the mediating role of self-efficacy has been confirmed widely in various groups, including nurses ${ }^{26}$ and medical students. ${ }^{27}$ Moreover, self-efficacy can also be used as a "moderator" to enhance or attenuate the impact of stressors or coping resources on psychosocial factors. Zou Tao et al.'s study mentioned that self-efficacy may moderate the relationship between sense of security and depression among the armed soldier population. ${ }^{28}$ Through Marta Makara-Studzińska et al.'s research, we know that selfefficacy moderated the association between pressure and professional burnout among firefighters. ${ }^{29}$ Through Gabriele Prati et al.'s research, we know that self-efficacy moderated the relationship between stress appraisal and quality of life among rescue workers. ${ }^{30}$ In summary, self-efficacy seems to be a related moderator of the relationship between POS and depressive symptoms in petroleum workers.

In conclusion, the aim of the study is firstly to explore the association between POS and depressive symptoms. Secondly, we will further explore whether self-efficacy can attenuate the relationship of POS with depressive symptoms. Finally, we investigated the prevalence of depressive symptoms among petroleum workers in China and propose intervention strategies to relieve depressive symptoms.

\section{Materials and Methods Study Subjects and Data Collection}

We conducted a cross-sectional survey in a petrochemical industry in northeastern China during the period from July to August 2018. Finally, 2200 workers were randomly selected. After briefly describing the study, we distributed a self-administered questionnaire directly to these workers. Trained investigators helped them complete the questionnaire anonymously. Investigators did not interfere in filling out the questionnaire. In this study, effective responses were received from 1836 (83.5\%) workers.

\section{Measurement of Depressive Symptoms}

The Chinese version of the Center for Epidemiologic Studies Depression Scale (CES-D) was used to measure depressive symptoms. ${ }^{31,32}$ The 20 -item Chinese version of the questionnaire was widely used in Chinese populations 
and had good reliability and validity. ${ }^{33}$ The CES-D measured the symptoms 1 week before the questionnaire. Every item has 4 responses with categories ranging from 0 "never" to 3 "always", and the total score ranged from 0 to 60 . Higher average score represents a higher depression level. A standard CES-D score $\geq 16$ presents depressive symptoms. Cronbach's alpha for the CES-D was 0.895 in this study.

\section{Measurement of Self-Efficacy}

The Chinese version of the General Self-Efficacy Scale (GSES) was used to measure self-efficacy. ${ }^{22}$ The GSES was widely used in Chinese populations. ${ }^{34,35}$ The scale consists of 10 items, and according to the personal feelings of the respondents, every item was answered with a 4-point Likert-type scale ranging from 1 "completely incorrect" to 4 "completely correct". The total score of the scale ranges from 10 to 40 , and a higher average score represents higher self-efficacy. In the present study, the Cronbach's $\alpha$ alpha for the GSES was 0.76

\section{Measurement of Perceived Organizational Support}

The Survey of Perceived Organizational Support (SPOS) scale was used to measure perceived organizational support. ${ }^{16}$ The SPOS scale includes 9 items and focuses on the evaluation and welfare of employees. Every item was answered with a 7-point Likert-type scale ranging from 1 "strongly disagree" to 7 "strongly agree". The total score of the scale ranges from 10 to 70 , and a higher average score represents higher POS levels. It has been widely used and validated in Chinese professional groups. ${ }^{36}$ Cronbach's alpha for the SPOS scale was 0.85 in the present study.

\section{Demographic and Working Factors}

In our research, demographic factors comprised age, gender, marital status, educational level, and monthly income. Age was divided into four groups: $\leq 30,31-40,41-50$, and $\geq 51$. Educational level was categorized as "senior high school or below" and "technical secondary school or above". Marital status was classified as "married/cohabited" and "single/divorced/widowed/separated". Monthly income (RMB) was classified as " $<4000$ " and " $\geq 4000$ ". Working characteristics including occupational category, night duty, and shift work were collected in our study. The occupational category was categorized as "refinery workers", "chemical workers", "transportation workers", and "other workers". Night duty and shift work are classified as "no" or "yes".

\section{Statistical Analysis}

Mean, standard deviation (SD), number (n) and percentage (\%) were used to describe the demographic, working characteristics, and psychological factors as appropriate. In our study: the independent variable was SPOS score; the dependent variable was CES-D score; the moderator variable was GSES score. The normality of these variables was proved by the Shapiro-Wilk test before statistical analysis. An independent-sample $t$-test or one-way ANOVA was applied to examine group differences of CES-D score, and Tukey's test was used for the post-hoc test. Correlations among SPOS score, CES-D score, and GSES score were examined by Pearson's correlation. Hierarchical regression analysis was used to prove the relationship of SPOS score and GSES score with CES-D score and to examine the moderating role of GSES score on the association of SPOS score with CES-D score. Besides age and gender, the working characteristics associated with CES-D score in univariate analysis $(P<0.05)$ were adjusted. Age, gender, and potential control variables were added in the first step. In the second step, SPOS score and GSES score were added. Finally, the product of SPOS score and GSES score was added in the last step. If the interaction effect had statistical significance, we will conduct simple slope analysis to visualize the interaction term. ${ }^{37}$ Before the regression analysis, the variables in the models were centralized. All statistical analyses were conducted by IBM SPSS Statistics 21.0 (IBM, Asia Analytics Shanghai, People's Republic of China), and a two-tailed $P<0.05$ was considered to have statistical significance.

\section{Results}

\section{Descriptive Statistics}

Demographic and working traits of study variables are presented in Table 1. In our research, 85.4\% (1568) workers were married or cohabited. 51.6\% (948) of workers had a senior high school or below education level, and there were $59.1 \%$ (1085) workers with a monthly income level of $<4000$ yuan. In all, the difference is statistically significant between occupational categories $(F=10.751$, $P<0.001$ ). 40.6\% (746) were refinery workers, and they reported a higher CES-D score than transportation workers $(P<0.05) .15 .4 \%$ (283) were chemical workers, and they reported a higher CES-D score than other workers 
Table I Demographic and Working Variables of Participants in Relation to CES-D Score

\begin{tabular}{|c|c|c|c|c|c|c|}
\hline \multirow[t]{2}{*}{ Variables } & \multirow[t]{2}{*}{$\mathbf{n}$} & \multirow[t]{2}{*}{$\%$} & \multicolumn{4}{|c|}{ CES-D Score } \\
\hline & & & Mean & SD & $F / t$ & $P$-value \\
\hline \multicolumn{7}{|l|}{ Age (years) } \\
\hline$\leq 30$ & 203 & 11.1 & 19.32 & $10.6 \mid$ & 1.957 & 0.119 \\
\hline $31-40$ & 416 & 22.7 & 20.47 & 11.17 & & \\
\hline $4 I-50$ & 863 & 47.0 & 19.29 & 10.32 & & \\
\hline$\geq 51$ & 354 & 19.3 & 18.73 & 10.01 & & \\
\hline \multicolumn{7}{|l|}{ Gender } \\
\hline Men & 1409 & 76.7 & 19.55 & 10.48 & 0.532 & 0.466 \\
\hline Women & 427 & 23.3 & 19.13 & 10.57 & & \\
\hline \multicolumn{7}{|l|}{ Marital status } \\
\hline Married/cohabiting & 1568 & 85.4 & 19.41 & 10.46 & 0.176 & 0.675 \\
\hline Single/divorced/widowed/separated & 268 & 14.6 & 19.70 & 10.77 & & \\
\hline \multicolumn{7}{|l|}{ Education level } \\
\hline Senior high school or below & 948 & 51.6 & 19.40 & 10.25 & 0.043 & 0.836 \\
\hline Technical secondary school or above & 888 & 48.4 & 19.50 & 10.77 & & \\
\hline \multicolumn{7}{|l|}{ Monthly income (RMB) } \\
\hline$<4000$ & 1085 & 59.1 & 19.56 & 10.72 & 0.311 & 0.577 \\
\hline$\geq 4000$ & 751 & 40.9 & 19.29 & 10.18 & & \\
\hline \multicolumn{7}{|l|}{ Occupational category } \\
\hline Refinery workers & 746 & 40.6 & $20.88^{\mathrm{a}}$ & 10.96 & 10.751 & $<0.001$ \\
\hline Chemical workers & 283 & 15.4 & $19.75^{\mathrm{b}}$ & 10.28 & & \\
\hline Transportation workers & 355 & 19.3 & $18.72^{\mathrm{a}}$ & 10.13 & & \\
\hline Other workers & 452 & 24.6 & $17.48^{\mathrm{b}}$ & 9.80 & & \\
\hline \multicolumn{7}{|l|}{ Night duty } \\
\hline Yes & 1111 & 60.5 & 20.26 & 10.92 & 16.956 & $<0.001$ \\
\hline No & 725 & 39.5 & $|8.2|$ & 9.690 & & \\
\hline \multicolumn{7}{|l|}{ Shift work } \\
\hline Yes & 985 & 53.6 & 20.36 & 10.86 & 16.130 & $<0.001$ \\
\hline No & 851 & 46.4 & 18.40 & 9.97 & & \\
\hline
\end{tabular}

Notes: ${ }^{\text {ab }}$ Tukey's test was used for post-hoc test, and the groups marked with different letters represent the statistical differences between the two comparisons. $p<0.05$. Abbreviations: SD, standard deviation; CES-D score, score of depressive symptoms.

$(P<0.05) .60 .5 \%$ (1111) of workers had night duty and they reported higher CES-D score $(t=16.956, P<0.001)$ than those who did not have night duty. 53.6\% (985) workers had shift work, and they presented a higher CES-D score $(t=16.130, P<0.001)$ compared with workers who did not have shift work.

\section{Correlations Among Continuous Variables}

Table 2 reports the correlations of SPOS score and GSES score with CES-D score. The mean scores of CES-D score, SPOS score, and GSES score were 19.45 \pm 10.50 , $41.36 \pm 13.09$, and $25.35 \pm 9.30$ respectively. Both SPOS
Table 2 Correlations Among Continuous Variables

\begin{tabular}{|l|l|l|l|l|l|}
\hline Variables & Mean & SD & $\begin{array}{l}\text { CES-D } \\
\text { Score }\end{array}$ & $\begin{array}{l}\text { SPOS } \\
\text { Score }\end{array}$ & $\begin{array}{l}\text { GSES } \\
\text { Score }\end{array}$ \\
\hline CES-D score & 19.45 & 10.50 & 1 & & \\
SPOS score & 41.36 & 13.09 & $-0.624 * *$ & 1 & \\
GSES score & 25.35 & 9.30 & $-0.459 * *$ & $0.267 * *$ & 1 \\
\hline
\end{tabular}

Notes: $* * p<0.01$ (two-tailed).

Abbreviations: SD, standard deviation; CES-D score, score of depressive symptoms; SPOS score, score of perceived organizational support; GSES score, score of self-efficacy.

score and GSES score were negatively correlated with CES-D score. Also, SPOS score was positively correlated with GSES score. 


\section{Hierarchical Regression Analysis}

Hierarchical regression analysis results of the factors correlated with CES-D score are displayed in Table 3. In step 1, the demographic and working factors (age, gender, shift work, night shift, occupational category) explained CES-D score $\left(F=6.484\right.$, adjusted $R^{2}=0.024$, $P<0.01)$. In step 2, SPOS score and GSES score were added and they ameliorated the model fitting of CES-D score $\left(F=190.888, \quad\right.$ adjusted $R^{2}=0.485, \quad \Delta R^{2}=0.461$, $P<0.01)$. SPOS score showed a significant main influence on CES-D score $(\beta=-0.538, \quad P<0.01)$, and GSES score showed a significant main influence on CES-D score $(\beta=-0.313, \quad P<0.01)$. The SPOS score $\times$ GSES score interaction term significantly explained an extra $9.7 \%$ of the variance $(F=253.932$, adjusted $\left.R^{2}=0.582, \Delta R^{2}=0.097, P<0.01\right)$ in step 3. The interaction term was positively correlated with CES-D score $(\beta=0.334, P<0.01)$. Simple slope analysis showed that when GSES score increases, the relationship between SPOS score and CES-D score reduces. It will be seen from this that the associations between SPOS score and CES-D score were gradually decreased in the low ( 1 SD below the mean, $\beta=-0.589, P<0.01$ ), mean $(\beta=-0.338, P<0.01)$, and high (1 SD above the mean, $\beta=-0.087, P<0.01)$ groups of GSES score. The interaction term is presented in Figure 1.

Table 3 Hierarchical Regression Results of CES-D Score

\begin{tabular}{|l|l|l|l|}
\hline Variables & Block I & Block 2 & Block 3 \\
\hline Age & -0.010 & -0.018 & -0.010 \\
Gender & -0.008 & -0.012 & -0.010 \\
Shift work & 0.038 & -0.014 & -0.017 \\
Night duty & $-0.059 *$ & 0.012 & -0.006 \\
\hline Occupational category & & & \\
Dummy_I & -0.039 & -0.020 & -0.014 \\
Dummy_2 & $-0.076^{* *}$ & $-0.041^{*}$ & -0.032 \\
Dummy_3 & $-0.115^{* *}$ & $-0.056^{* *}$ & $-0.035^{*}$ \\
\hline SPOS score & & $-0.538^{* *}$ & $-0.422^{* *}$ \\
GSES score & & $-0.313^{* *}$ & $-0.379 * *$ \\
Interaction & & & $0.334^{* *}$ \\
$F$ & $6.484^{* *}$ & $190.888^{* *}$ & $253.932^{* *}$ \\
Adjusted $R^{2}$ & 0.024 & 0.485 & 0.582 \\
$\Delta R^{2}$ & 0.024 & 0.461 & 0.097 \\
\hline
\end{tabular}

Notes: Gender, women versus men; shift work, no versus yes; night duty, no versus yes; Dummy_I, chemical workers versus refinery workers; Dummy_2, transportation workers versus refinery workers; Dummy_3, other workers versus refinery workers. ${ }^{*} p<0.05$; ${ }^{* *} p<0.01$ (two-tailed).

Abbreviations: CES-D score, score of depressive symptoms; SPOS score, score of perceived organizational support; GSES score, score of self-efficacy.

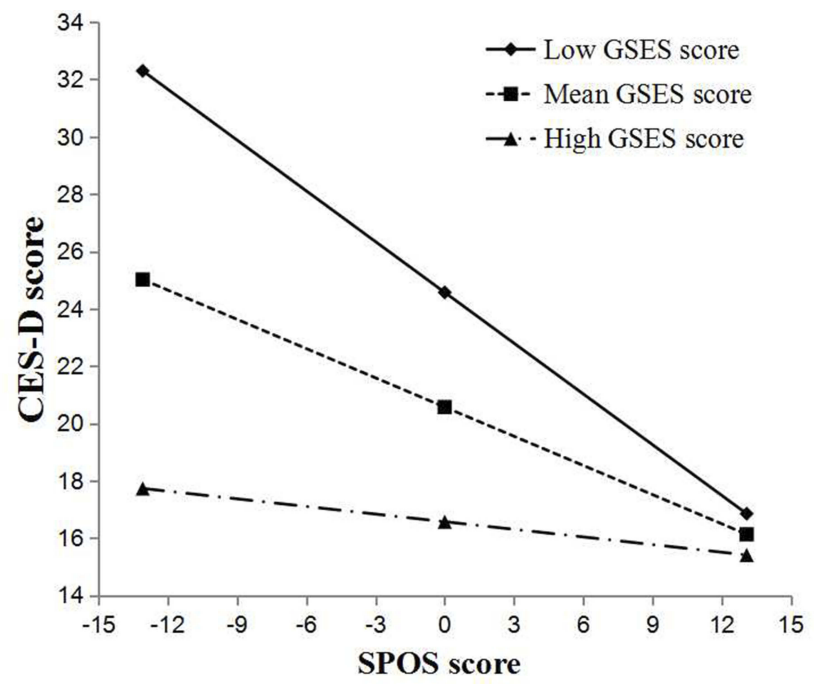

Figure I Simple slope plot of interaction between SPOS score and GSES score on CES-D score.

Notes: Low, I SD below the mean; high, I SD above the mean.

Abbreviations: SD, standard deviation; CES-D score, score of depressive symptoms; SPOS score, score of perceived organizational support; GSES score, score of self-efficacy.

\section{Discussion}

As far as we know, this research was the first to confirm the moderating role of self-efficacy on the relationship between POS and depressive symptoms among petroleum workers in China. In this research, POS had significantly negative correlation with depressive symptoms, and self-efficacy attenuate the association between POS and depressive symptoms. We also found that $63.2 \%$ of the petroleum workers investigated in our study had depressive symptoms. The prevalence of depressive symptoms in Chinese petroleum workers was higher than underground coal miners according to previous research. ${ }^{38}$ The mean score of depressive symptoms was higher than in other Chinese occupational populations. ${ }^{7,39}$ So, it is necessary to reduce the depressive symptoms of petroleum workers in China. Among demographic and working variables, occupational category, shift work, and night duty were associated with depressive symptoms. These correlations were already discussed in previous research. ${ }^{40-42}$ Understanding the working factors of depressive symptoms is helpful to promote a comprehensive model for interventions in petroleum workers.

The study showed that POS was negatively related to depressive symptoms, which was consistent with previous research. ${ }^{20}$ We found that workers with a high level of POS are less likely to experience depressive symptoms. This may be because when their organization cares about their well-being and values their contributions, they can feel an effective sense of organizational support that causes positive work attitudes and job satisfaction, and 
then has positive effects on their mental health. ${ }^{18,19,43}$ Through previous research, POS was found to be able to relieve depressive symptoms in different groups. ${ }^{20,21}$ This meant that POS was a positive coping resource for depressive symptoms among petroleum workers in China. Therefore, to relieve the depressive symptoms of petroleum workers, enterprise administrators should give more organizational support to their employees.

Furthermore, our study also found that self-efficacy was negatively related to depressive symptoms and can attenuate the association between POS and depressive symptoms. It showed that if petroleum workers feel more sense of self-efficacy, they can better reduce their depressive symptoms at a lower POS level. The result was concordant with our hypothesis. This relationship between self-efficacy and depressive symptoms has been widely discussed in workers of different genders and different countries. ${ }^{44,45}$ A high sense of self-efficacy can reduce the depressive symptoms of workers. One reason for this result may be that those with higher self-efficacy have more confidence, so they have better well-being and feel more like they belong. ${ }^{46}$ This showed that the belief in one's competence to cope with a broad range of stressful or challenging demands is considered one of the most important coping resources for overcoming depressive symptoms of petroleum workers in China. According to our study, we can reduce depressive symptoms by improving self-efficacy of petroleum workers in China.

Therefore, we can improve POS or self-efficacy to alleviate depressive symptoms of petroleum workers. Petrochemical enterprises should ensure the fairness of salary, welfare, reward, and promotion of petroleum workers, pay attention to their emotional needs, provide help in case of difficulties, respect and value their contributions, provide training opportunities for them, and provide necessary information and material assistance for work. Previous studies have shown that these measures can improve the POS of workers. ${ }^{47}$ For improving selfefficacy, petroleum workers can regularly watch inspirational videos of successful people in the same field. They can also set a timer to stand and stretch several times a day, and adding $1 \mathrm{~km}$ to the total run distance each week is available. Petrochemical enterprises should encourage petroleum workers, implement bonus policies, and hold praise conferences and so on. These measures have been proven to improve self-efficacy of workers. ${ }^{48,49}$

However, there are still several limitations to this study. Firstly, although our data meet the four conditions of linear regression - linear trend, independence, normality, homogeneity of variance - it is hard to study the causality between the variables. Therefore, longitudinal studies should be conducted to confirm these findings. Secondly, the sample in our study only includes workers in one petrochemical industry. A large sample size and better response rate can well represent the petroleum workers, which is helpful to the promotion of our research results. Thirdly, the correlation between research variables may be influenced by the results of selfadministered questionnaires. Although, we have taken many effective process control measures to reduce common methodological deviations, including using highly reliable and effective measurement tools, establishing measurement intervals between independent variables and dependent variables, guaranteeing anonymity of respondents, and ensuring the accuracy of the answers.

\section{Conclusion}

POS and self-efficacy were negatively correlated with depressive symptoms. Self-efficacy can weaken the relationship between POS and depressive symptoms. The prevalence of depressive symptoms among Chinese petroleum workers is high. In the prevention and treatment of depressive symptoms among petroleum workers, besides providing enough POS, self-efficacy intervention should also be considered.

\section{Ethical Approval}

The study protocol was in accordance with the ethical standards, and was approved by the Committee on Human Experimentation of China Medical University.

\section{Informed Consent}

Written informed consent was obtained from all petroleum workers.

\section{Author Contributions}

All authors contributed to data analysis, drafting or revising the article, gave final approval of the version to be published, and agree to be accountable for all aspects of the work.

\section{Disclosure}

The authors report no conflicts of interest in this work.

\section{References}

1. Saneei P, Esmaillzadeh A, Hassanzadeh Keshteli A, et al. Combined healthy lifestyle is inversely associated with psychological disorders among adults. PLoS One. 2016;11(1):e0146888. doi:10.1371/journal. pone. 0146888 
2. Lloyd, Bruce. The World Health Report 2001: Mental Health: New Understanding, New Hope, World Health Organization. Long Range Planning. 2002;35(5):558.

3. Niedhammer I, David S, Degioanni S. Association between workplace bullying and depressive symptoms in the French working population. J Psychosom Res. 2006;61(2):251-259. doi:10.1016/j. jpsychores.2006.03.051

4. Fushimi M, Saito S, Shimizu T. Prevalence of depressive symptoms and related factors in Japanese employees as measured by the Center for Epidemiologic Studies Depression Scale (CES-D). Community Ment Hlt J. 2013;49(2):236-242. doi:10.1007/s10597-012-9542-x

5. Okechukwu CA, Ayadi AME, Tamers SL, et al. Household food insufficiency, financial strain, work-family spillover, and depressive symptoms in the working class: the work, family, and health network study. Am J Public Health. 2012;102(1):126-133. doi:10.2105/ AJPH.2011.300323

6. Chunli D. More than half of occupational population are in a state of depression in China. Saf Health. 2012;1:34.

7. Dai J, Yu H, Wu J, et al. Analysis on the association between job stress factors and depression symptoms. Wei Sheng Yan Jiu. 2010;39 (3):342-346. PMID: 20568467

8. Adler DA, McLaughlin TJ, Rogers WH, et al. Job performance deficits due to depression. Am $J$ Psychiatry. 2006;163 (9):1569-1576. doi:10.1176/ajp.2006.163.9.1569

9. Goetzel RZ, Long SR, Ozminkowski RJ, et al. Health, absence, disability, and presenteeism cost estimates of certain physical and mental health conditions affecting U.S. employers. J Occup Environ Med. 2004;46:398-412. doi:10.1097/01.jom.0000121151.40413.bd

10. Lerner D, Adler DA, Chang H, et al. Unemployment, job retention, and productivity loss among employees with depression. Psychiatr Serv. 2004;55(12):1371-1378. doi:10.1176/appi.ps.55.12.1371

11. Rao W-W, Xu D-D, Cao X-L, et al. Prevalence of depressive symptoms in children and adolescents in China: a meta-analysis of observational studies. Psychiatry Res. 2019;272:790-796. doi:10.1016/j. psychres.2018.12.133

12. $\mathrm{Gu} \mathrm{G}, \mathrm{Yu} \mathrm{S}, \mathrm{Wu} \mathrm{H}$, et al. The effect of occupational stress on depression symptoms among 244 policemen in a city. Chi J Prev Med. 2015;49(10):924-929.PMID: 26813728

13. Chen WQ, Wong TW, Yu TS. Mental health issues in Chinese offshore oil workers. Occup Med. 2009;59(8):545-549. doi:10.1093/ occmed/kqp 118

14. Nielsen MB, Tvedt SD, Matthiesen SB. Prevalence and occupational predictors of psychological distress in the offshore petroleum industry: a prospective study. Int Arch Occup Environ Health. 2013;86 (8):875-885. doi:10.1007/s00420-012-0825-x

15. Netterstr B, Conrad MN, Bech P, et al. The relationship between work-related psychosocial factors and the development of depression. Epidemiol Rev. 2008;30(1):118-132. doi:10.1093/epirev/mxn004

16. Eisenberger R, Huntington R, Hutchison S, et al. Perceived organizational support. J. Appl. Psychol. 1986;71(3):500-507. doi:10.1037/ 0021-9010.71.3.500

17. Kurtessis JN, Eisenberger R, Ford MT, et al. Perceived organizational support: a meta-analytic evaluation of organizational support theory (article). J Manage. 2017;43(6):1854-1884. doi:10.1177/0149206 315575554

18. Rhoades L, Eisenberger R. Perceived organizational support: a review of the literature. $J$ Appl Psychol. 2002;87:698-714. doi:10.1037/0021-9010.87.4.698

19. Wright PJ, Kim PY, Wilk JE, et al. The effects of mental health symptoms and organizational climate on intent to leave the military among combat veterans. Mil. Med. 2012;177:773-779. doi:10.7205/ MILMED-D-11-00403

20. Liu L, Hu S, Wang L, et al. Positive resources for combating depressive symptoms among Chinese male correctional officers: perceived organizational support and psychological capital. BMC Psychiatry. 2013;13:89. doi:10.1186/1471-244X-13-89
21. Ma L, Hu S, Wang L. Study on relationship between effort-reward imbalance and depressive tendency among prison policemen: the mediation role of perceived organizational support. Pract Prevent Med. 2013;20:41.

22. Luszczynska A, Scholz U, Schwarzer R. The general self-efficacy scale: multicultural validation studies. $J$ Psychol. 2005;139 (5):439-457. doi:10.3200/JRLP.139.5.439-457

23. Bandura A. Self-efficacy: toward a unifying theory of behavioral change. Psychol Rev. 1977;84(2):191-215. doi:10.1037/0033-295X.84.2.191

24. Pu J, Hou HP, Ma RY. Direct and indirect effects of self-efficacy on depression: the mediating role of dispositional optimism. Curr Psychol. 2017;36(3):410-416. doi:10.1007/s12144-016-9429-z

25. Sympa P, Vlachou E, Kazakos K, et al. Depression and self-efficacy in patients with type 2 diabetes in Northern Greece. Endocr Metab Immune Disord Drug Targets. 2018;18(4):371-378. doi:10.2174/ 1871530317666171120154002

26. Hsieh Y-H, Wang H-H, Ma S-C. The mediating role of self-efficacy in the relationship between workplace bullying, mental health and an intention to leave among nurses in Taiwan. Int J Occup Med Environ Health. 2019;32(2):245-254. doi:10.13075/ijomeh.1896.01322

27. Huang L, Liang Y-L, Hou -J-J, et al. General self-efficacy mediates the effect of family socioeconomic status on critical thinking in Chinese medical students. Front Psychol. 2019. doi:10.3389/fpsyg

28. Tao Z, Hua W, Wenquan T, et al. Moderating effect of self-efficacy on sense of security and depression among the armed soldier population. J Guiyang Med Coll. 2012;37(4):369-375.

29. Makara-Studzińnska M, Golonka K, Izydorczyk B Self-efficacy as a moderator between stress and professional burnout in firefighters. Int J Environ Res Public Health. 2019;16(2):183. doi:10.3390/ijerph 16020183

30. Prati G, Pietrantoni L, Cicognani E. Self-efficacy moderates the relationship between stress appraisal and quality of life among rescue workers. Anxiety Stress Coping. 2010;23(4):463-470. doi:10.1080/ 10615800903431699

31. Radloff LS. The CES-D scale: a self-report depression scale for research in the general population. Appl Psychol Meas. 1977;1 (3):385-401. doi:10.1177/014662167700100306

32. Liu XC, Tang MQ. The comparison of SDS and CES-D on college students' depressive symptoms. Chin Ment Health J. 1995;9:19-21.

33. Liu L, Chang Y, Fu J, et al. The mediating role of psychological capital on the association between occupational stress and depressive symptoms among Chinese physicians: a cross-sectional study. $B M C$ Public Health. 2012;12:219. doi:10.1186/1471-2458-12-219

34. Wang ZY, Liu L, Shi M, Wang L. Exploring correlations between positive psychological resources and symptoms of psychological distress among hematological cancer patients: a cross-sectional study. Psychology Health Med. 2016;21(5):571-582. doi:10.1080/ 13548506.2015.1127396

35. Yang YL, Liu L, Wang XX, et al. Prevalence and associated positive psychological variables of depression and anxiety among Chinese cervical cancer patients: a cross-sectional study. PLoS One. 2014;9 (4):e94804. doi:10.1371/journal.pone.0094804

36. Fu J, Sun W, Wang Y, et al. Improving job satisfaction of Chinese doctors: the positive effects of perceived organizational support and psychological capital. Public Health. 2013;127(10):946-951. doi:10.1016/j.puhe.2012.12.017

37. Bolin JH.Hayes, Andrew F. (2013). Introduction to mediation, moderation, and conditional process analysis: a regression-based approach. New York, NY: the Guilford Press.J EDUC MEAS 2014;51(3):335-337. doi:10.1111/jedm.12050

38. Liu L, Wang L, Chen J. Prevalence and associated factors of depressive symptoms among chinese underground coal miners. Biomed Res Int. 2014;2014:987305. doi:10.1155/2014/987305

39. Liu L, Pang R, Sun W, et al. Functional social support, psychological capital, and depressive and anxiety symptoms among people living with HIV/AIDS employed full-time. BMC Psychiatry. 2013;13:324. doi:10.1186/1471-244X-13-324 
40. Pavičić Žeželj S, Cvijanović Peloza O, Mika F, et al. Anxiety and depression symptoms among gas and oil industry workers. Occup Med. 2019;69(1):22-27. doi:10.1093/occmed/kqy170

41. Ljosa CH, Tyssen R, Lau B. Mental distress among shift workers in Norwegian offshore petroleum industry-relative influence of individual and psychosocial work factors. Scand J Work Environ Health. 2011;37(6):551-555. doi:10.5271/sjweh.3191

42. Berthelsen M, Pallesen S, Bjorvatn B, et al. Shift schedules, work factors, and mental health among onshore and offshore workers in the Norwegian petroleum industry. Ind Health. 2015;53(3):280-292. doi:10.2486/indhealth.2014-0186

43. Zumrah AR, Boyle S. The effects of perceived organizational support and job satisfaction on transfer of training. Personnel Rev. 2015;44 (2):236-254. doi:10.1108/PR-02-2013-0029

44. Taneichi H, Asakura M, Sairenchi T, et al. Low self-efficacy is a risk factor for depression among male Japanese workers: a cohort study. Ind Health. 2013;51(4):452-458. doi:10.2486/indhealth.2013-0021
45. Hwang W, Kim J, Rankin S. Depressive symptom and related factors: a cross-sectional study of korean female workers working at traditional markets. Int J Environ Res Public Health. 2017;14(12):1465. doi:10.3390/ijerph14121465

46. Salles A. Self-efficacy as a measure of confidence. JAMA Surg. 2017;152(5):506. doi:10.1001/jamasurg.2017.0035

47. Zhu L. Fuzzy comprehensive model for evaluating degree of perceived organizational support of staffs. J Univ Shanghai Sci Technol. 2013;35(1):33-36

48. Buckworth J. Promoting self-efficacy for healthy behaviors. ACSMs Health Fit J. 2017;21(5):40-42. doi:10.1249/FIT.0000000000000318

49. Bingöl TY, Batik MV, Hosoglu R, Firinci KA. Psychological resilience and positivity as predictors of self-efficacy. Asian J Educ Training. 2019;5(1):63-69. doi:10.20448/journal.522.2019.51.63.69
Psychology Research and Behavior Management

\section{Publish your work in this journal}

Psychology Research and Behavior Management is an international, peer-reviewed, open access journal focusing on the science of psychology and its application in behavior management to develop improved outcomes in the clinical, educational, sports and business arenas. Specific topics covered in the journal include: Neuroscience, memory and decision making; Behavior modification and management; Clinical

\section{Dovepress}

applications; Business and sports performance management; Social and developmental studies; Animal studies. The manuscript management system is completely online and includes a very quick and fair peer-review system, which is all easy to use. Visit http://www. dovepress.com/testimonials.php to read real quotes from published authors. 